\title{
Chamomile: A herbal medicine of the past with a bright future (Review)
}

\author{
JANMEJAI K. SRIVASTAVA ${ }^{1,2,4}$, ESWAR SHANKAR ${ }^{1,2}$ and SANJAY GUPTA ${ }^{1-3}$ \\ Department of Urology and Nutrition, ${ }^{1}$ Case Western Reserve University; ${ }^{2}$ University Hospitals Case Medical Center; \\ ${ }^{3}$ Case Comprehensive Cancer Center, Cleveland, OH 44106, USA
}

Received August 4, 2010; Accepted August 30, 2010

DOI: $10.3892 / \mathrm{mmr} .2010 .377$

\begin{abstract}
Chamomile is one of the most ancient medicinal herbs known to mankind. It is a member of the Asteraceael Compositae family and is represented by two common varieties, German Chamomile (Chamomilla recutita) and Roman Chamomile (Chamaemelum nobile). The dried flowers of chamomile contain many terpenoids and flavonoids, which contribute to its medicinal properties. Chamomile preparations are commonly used for many human ailments, including hay fever, inflammation, muscle spasms, menstrual disorders, insomnia, ulcers, wounds, gastrointestinal disorders, rheumatic pain and hemorrhoids. Essential oils of chamomile are used extensively in cosmetics and aromatherapy. Numerous preparations of chamomile have been developed, the most popular being in the form of herbal tea, of which more than one million cups are consumed every day. In this review, we describe the use of chamomile in traditional medicine with regard to evaluating its curative and preventive properties, and highlight recent findings that may contribute to its development as a therapeutic agent promoting human health.
\end{abstract}

Correspondence to: Dr Sanjay Gupta, Department of Urology, Case Western Reserve University, 10900 Euclid Avenue, Cleveland, OH 44106, USA

E-mail: sanjay.gupta@case.edu

Present address: ${ }^{4}$ Amity Institute of Biotechnology (Mango Orchard Campus), Amity University, Lucknow Campus, Viraj Khand 5, Gomti Nagar, Lucknow, India

Abbreviations: ACTH, adrenocorticotropic hormone; ASA, American Society of Anesthesiologists; BDZ, benzodiazepine; CAM, complementary and alternative medicine; COX, cyclooxygenase; 5-FU, 5-fluorouracil; GABA, $\gamma$-aminobutyric acid; GAD, generalized anxiety disorder; LPS, lipopolysaccharide; SERMs, selective estrogen receptor modulators

Key words: chamomile, dietary agents, flavonoids, polyphenols, human health

\section{Contents}

1. Introduction

2. Bioactive constituents of chamomile

3. Healthcare preparations with chamomile

4. Traditional uses of chamomile

5. Scientific evaluation of chamomile

6. Contraindications and safety issues with chamomile

7. Conclusions

\section{Introduction}

The effect of plants on human health has been documented for thousands of years (1-3). Herbs have been integral to both traditional and non-traditional forms of medicine dating back at least 5000 years $(2,4-6)$. The enduring popularity of herbal medicines may be explained by the tendency of herbs to work slowly, usually with minimal toxic side effects. One of the most common herbs used for medicinal purposes is chamomile, whose standardized tea and herbal extracts are prepared from dried flowers of the Matricaria species. Chamomile is one of the oldest, most widely used and well-documented medicinal plants in the world, and has been recommended for a variety of healing applications (7). Chamomile is native to the Old World and is a member of the daisy family (Asteraceae or Compositae). The hollow, bright gold cones of the flowers are packed with disc or tubular florets, and are ringed with approximately fifteen white ray or ligulate florets. Chamomile is widely represented by two known varieties, German chamomile (Matricaria chamomilla) and Roman chamomile (Chamaemelum nobile) (8). In this review, we discuss the use and possible merits of chamomile, examining its historical use and recent scientific and clinical evaluations of its potential in the management of various human ailments.

\section{Bioactive constituents of chamomile}

Different classes of bioactive constituents are present in chamomile. These have been isolated and used as medicinal preparations and cosmetics (9). The plant contains $0.24-1.9 \%$ volatile oil, composed of a variety of separate oils. When exposed to steam distillation, the oil ranges in color from brilliant blue to deep green when fresh, but turns to dark yellow 
after storage. Despite fading, the oil does not lose its potency. Approximately 120 secondary metabolites have been identified in chamomile, including 28 terpenoids and 36 flavonoids $(10,11)$. The principal components of the essential oil extracted from the German chamomile flowers are the terpenoids $\alpha$-bisabolol and its oxide azulenes, including chamazulene and acetylene derivatives. Chamazulene and bisabolol are very unstable and are best preserved in an alcoholic tincture. Essential oil of Roman chamomile contains less chamazulene and is mainly constituted from esters of angelic and tiglic acid. It also contains farnesene and $\alpha$-pinene. Roman chamomile contains up to $0.6 \%$ of sesquiterpene lactones of the germacranolide type, mainly nobilin and 3-epinobilin. Both $\alpha$-bisabolol and bisabolol oxides $\mathrm{A}$ and $\mathrm{B}$, as well as chamazulene or azulenesse, farnesene and spiro-ether quiterpene lactones, glycosides, hydroxycoumarins, flavonoids (apigenin, luteolin, patuletin and quercetin), coumarins (herniarin and umbelliferone), terpenoids and mucilage are considered to be the major bioactive ingredients $(12,13)$. Other major constituents of the flowers include several phenolic compounds, primarily the flavonoids apigenin, quercetin, patuletin as glucosides and various acetylated derivatives. Among the flavonoids, apigenin is the most promising compound. It is present in very small quantities as free apigenin, but predominantly exists in the form of various glycosides (14-18).

\section{Healthcare preparations of chamomile}

Chamomile preparations take various forms. Dry powder of chamomile flower is recommended and used by many individuals for traditionally established health problems. Medicinal ingredients are normally extracted from the dry flowers of chamomile using water, ethanol or methanol as solvents, with the corresponding extracts known as aqueous, ethanolic (alcoholic) and/or methanolic extracts. Optimum chamomile extracts contain approximately 50\% alcohol. Normally, standardized extracts contain $1.2 \%$ apigenin, one of the most effective bioactive agents. Aqueous extracts, for example in the form of tea, contain quite low concentrations of free apigenin, but include high levels of apigenin-7- $O$-glucoside. Oral consumption of infusions of chamomile is recommended by the German Commission E $(19,20)$. Chamomile tea is one of the world's most popular herbal teas. Roughly a million cups of chamomile tea are consumed each day. Chamomile tea bags containing chamomile flower powder, either pure or blended with other popular medicinal herbs, are readily available on the market. Chamomile tincture may also be prepared as one part chamomile flower in four parts of water having $12 \%$ grain alcohol, which is used to correct summer diarrhea in children and also used with purgatives to prevent cramping. Chamomile flowers are extensively used, either alone or in combination with crushed poppy-heads, as a poultice or hot foment for inflammatory pain or congestive neuralgia, and in cases of external swelling, such as facial swelling associated with underlying infection or abscess. The whole chamomile plant is used for making herbal beers, and also in lotions, for external application in cases of toothache, earache or neuralgia, and in cases of external swelling (20). It is also frequently used as a bath additive, recommended for soothing ano-genital inflammation (21). The tea infusion is used as a wash or gargle for inflammation of the mucous membranes of the mouth and throat $(22,23)$. Inhalation of the vaporized essential oils derived from chamomile flowers is recommended to relieve anxiety and general depression. Chamomile oil is a popular ingredient in aromatherapy and hair care $(24,25)$. Roman chamomile is widely used in cosmetic preparations and has a soothing and softening effect on the skin $(26,27)$.

\section{Traditional uses of chamomile}

Traditionally, chamomile has been used for centuries as an anti-inflammatory, antioxidant, mild astringent and healing medicine (28). As a traditional medicine, it is used to treat wounds, ulcers, eczema, gout, skin irritations, bruises, burns, canker sores, neuralgia, sciatica, rheumatic pain, hemorrhoids, mastitis and other ailments $(29,30)$. Externally, chamomile has been used to treat diaper rash, cracked nipples, chicken pox, ear and eye infections, disorders of the eyes including blocked tear ducts, conjunctivitis, nasal inflammation and poison ivy $(31,32)$. Chamomile is widely used to treat inflammations of the skin and mucous membranes, and for various bacterial infections of the skin, oral cavity, gums, and respiratory tract. Chamomile in the form of an aqueous extract has been commonly used as a mild sedative to calm nerves and reduce anxiety to treat hysteria, nightmares, insomnia and other sleep problems (33). Chamomile has been valued as a digestive relaxant, and has been used to treat various gastrointestinal disturbances including flatulence, indigestion, diarrhea, anorexia, motion sickness, nausea and vomiting $(34,35)$. Chamomile has also been used to treat colic, croup and fevers in children (36). Additionally, it has been used as an emmenagogue and a uterine tonic in women. It is also effective in alleviating arthritis, back pain, bedsores and stomach cramps.

\section{Scientific evaluation of chamomile}

Anti-inflammatory and antiphlogistic properties. The flowers of chamomile contain 1-2\% volatile oils including $\alpha$-bisabolol, $\alpha$-bisabolol oxides A and B and matricin (usually converted to chamazulene) as well as other flavonoids that possess antiinflammatory and antiphlogistic properties $(12,19,35,36)$. A study in human volunteers demonstrated that chamomile flavonoids and essential oils penetrate below the skin surface into the deeper skin layers (37). This is key to their usefulnes as topical antiphlogistic (anti-inflammatory) agents. One of chamomile's anti-inflammatory activities involves the inhibition of lipopolysaccharide (LPS)-induced prostaglandin $\mathrm{E}_{2}$ release and the attenuation of cyclooxygenase (COX-2) enzyme activity, without the constitutive form, COX-1, being affected (38).

Anticancer activity. Most evaluations of tumor growth inhibition by chamomile involve studies with apigenin, one of the bioactive constituents of chamomile. Studies using preclinical models of skin, prostate, breast and ovarian cancer have shown it to have promising growth inhibitory effects (39-43). In a recently conducted study, chamomile extracts were shown to have minimal growth inhibitory effects in normal cells, but showed a significant reduction in cell viability in various human cancer cell lines. Chamomile exposure induced apop- 
tosis in cancer cells, but not in normal cells at similar doses (18). The efficacy of the novel agent TBS-101, a mixture of seven standardized botanical extracts including chamomile, has recently been tested. The results confirm it to have an outstanding safety profile with significant anticancer activities against androgen-refractory human prostrate cancer PC-3 cells, both in vitro and in vivo (44).

Common cold. Common cold (acute viral nasopharyngitis) is the most common human disease. It is a mild viral infectious disease of the upper respiratory system. Typically, a common cold is not life-threatening, although its complications (such as pneumonia) can lead to death, if not properly treated. Studies indicate that inhaling steam with chamomile extract has been helpful in relieving common cold symptoms (45); however, further research is needed to confirm these findings.

Cardiovascular conditions. It has been suggested that the regular use of flavonoids consumed in food may reduce the risk of death from coronary heart disease in elderly men (46). A study assessed the flavonoid intake of 805 men aged 65-84 years who were followed up for 5 years. Flavonoid intake (analyzed in tertiles) was significantly inversely associated with mortality from coronary heart disease and showed an inverse relation with the incidence of myocardial infarction. In another study (47) involving twelve patients with cardiac disease who underwent cardiac catheterization, hemodynamic measurements obtained prior to and $30 \mathrm{~min}$ after the oral ingestion of chamomile tea exhibited a small but significant increase in mean brachial artery pressure. No other significant hemodynamic changes were observed after chamomile consumption. Ten of the twelve patients fell into a deep sleep shortly after drinking the beverage. A large well-designed randomized controlled trial is needed to assess the potential value of chamomile in improving cardiac health.

Colic/diarrhea conditions. An apple pectin-chamomile extract may help shorten the course of diarrhea in children, as well as relieve symptoms associated with the condition (47). Two clinical trials have evaluated the efficacy of chamomile for the treatment of colic in children. In these trials, chamomile tea was combined with other herbs (German chamomile, vervain, licorice, fennel, balm mint) for administration. In a prospective randomized double-blind placebo-controlled study, 68 healthy term infants (2-8 weeks old) who had colic received either herbal tea or a placebo (glucose, flavoring). Each infant was offered treatment with every bout of colic, up to $150 \mathrm{ml} /$ dose, no more than three times a day. After 7 days of treatment, parents reported that the tea eliminated the colic in $57 \%$ of the infants, whereas the placebo was helpful in only $26 \%(\mathrm{P}<0.01)$. No adverse effects with regard to the number of nighttime awakenings were noted in either group (48). Another study examined the effects of a chamomile extract and apple pectin preparation in 79 children (aged 0.5-5.5 years) with acute non-complicated diarrhea who received either the chamomile/pectin preparation $(n=39)$ or a placebo $(n=40)$ for 3 days. Diarrhea ended sooner in children treated with chamomile and pectin $(85 \%)$ than in the placebo group (58\%) (49). These results indicate that chamomile can be used safely to treat infant colic disorders.
Eczema. Topical applications of chamomile have been shown to be moderately effective in the treatment of atopic eczema (50). It was found to be approximately $60 \%$ as effective as $0.25 \%$ hydrocortisone cream (51). Roman chamomile of the Manzana type in the cream Kamillosan ${ }^{\circledR}$ may ease discomfort associated with eczema. The Manzana type of chamomile is rich in active ingredients and does not exhibit chamomile-related allergenic potential. In a partially doubleblind randomized study carried out as a half-side comparison, Kamillosan cream was compared with $0.5 \%$ hydrocortisone cream and a placebo consisting only of vehicle cream in patients suffering from medium-degree atopic eczema (52). After 2 weeks of treatment, Kamillosan cream showed a slight superiority over $0.5 \%$ hydrocortisone and a marginal difference as compared to the placebo. Further research is needed to evaluate the usefulness of topical chamomile in managing eczema.

Gastrointestinal conditions. Chamomile is traditionally used for the treatment of numerous gastrointestinal conditions, including digestive disorders, 'spasm' or colic, upset stomach, flatulence (gas), ulcers and gastrointestinal irritation (53). Chamomile is particularly helpful in dispelling gas, soothing the stomach, and relaxing the muscles that move food through the intestines. The protective effect of a commercial preparation (STW5, Iberogast), containing the extracts of bitter candy tuft, lemon balm leaf, chamomile flower, caraway fruit, peppermint leaf, liquorice root, Angelica root, milk thistle fruit and greater celandine herb against the development of gastric ulcers has been previously reported (54). STW5 extracts produced a dose-dependent anti-ulcerogenic effect associated with reduced acid output, increased mucin secretion, an increase in prostaglandin $\mathrm{E}_{2}$ release and a decrease in leukotrienes. The results obtained demonstrated that STW5 not only lowered gastric acidity as effectively as a commercial antacid, but was more effective in inhibiting secondary hyperacidity (54).

Hemorrhoids. Studies suggest that chamomile ointment may improve hemorrhoids. Tinctures of chamomile can also be used in a sitz bath format. Tincture of Roman chamomile may reduce the inflammation associated with hemorrhoids $(55,56)$.

Promotion of health. It has been claimed that consumption of chamomile tea boosts the immune system and helps fight infections associated with colds. The health promoting benefits of chamomile were assessed in a study involving fourteen volunteers who each drank five cups of the herbal tea daily for two consecutive weeks. Daily urine samples were taken and tested throughout the study, both before and after drinking chamomile tea. Drinking chamomile was associated with a significant increase in urinary levels of hippurate and glycine, which have been associated with increased antibacterial activity (57). In another study, chamomile relieved hypertensive symptoms and decreased systolic blood pressure significantly, increasing urinary output (58). Additional studies are required before a more definitive link between chamomile and its alleged health benefits can be established. 
Inflammatory conditions. Inflammation is associated with many gastrointestinal complaints, such as esophageal reflux, diverticular disease and inflammatory disease (59-61). Studies in preclinical models suggest that chamomile inhibits Helicobacter pylori, the bacteria that contribute to stomach ulcers (60). Chamomile is believed to be helpful in reducing smooth muscle spasms associated with various gastrointestinal inflammatory disorders. Chamomile is often used to treat mild skin irritations, including sunburn, rashes, sores and even eye inflammations (62-65), but its value in treating these conditions has not been demonstrated through evidence-based research.

Mucositis. Mouth ulcers are a common condition with a variety of etiologies (66). Stomatitis is a major dose-limiting toxicity resulting from bolus 5-fluorouracil (5-FU)-based chemotherapy regimens. In a double-blind placebo-controlled clinical trial including 164 patients (22), patients were entered into the study at the time of their first cycle of 5-FU-based chemotherapy and were randomized to receive a chamomile or placebo mouthwash thrice daily for 14 days. There was no suggestion of any difference in the incidence of stomatitis between the patients randomized to either protocol group, nor any suggestion of toxicity. Similar results were obtained in another prospective trial on chamomile in this situation (23). Data obtained from these clinical trials did not support the pre-study hypothesis that chamomile decreases 5-FU-induced stomatitis. Thus it remains unclear whether chamomile is helpful in this situation.

Osteoporosis. Osteoporosis is a metabolic bone disease resulting from low bone mass (osteopenia) due to excessive bone resorption. Sufferers are prone to bone fractures from relatively minor trauma. Agents including selective estrogen receptor modulators or SERMs, biphosphonates and calcitonin are frequently used to prevent bone loss. To prevent bone loss that occurs with increasing age, chamomile extract was evaluated for its ability to stimulate the differentiation and mineralization of osteoblastic cells. Chamomile extract was shown to stimulate osteoblastic cell differentiation and to exhibit an anti-estrogenic effect, suggesting an estrogen receptor-related mechanism (67). However, further studies are required before it can be considered for clinical use.

Sleep aid/sedation. Traditionally, chamomile preparations such as tea and essential oil aromatherapy have been used to treat insomnia and to induce sedation (calming effects). Chamomile is widely regarded as a mild tranquillizer and sleep-inducer. Sedative effects may be due to the flavonoid apigenin, which binds to benzodiazepine receptors in the brain (68). Studies in preclinical models have shown anticonvulsant and CNS depressant effects, respectively. However, clinical trials are notably absent, although ten cardiac patients were reported to have immediately fallen into a deep sleep lasting for $90 \mathrm{~min}$ after drinking chamomile tea (47). Chamomile extracts exhibit benzodiazepine-like hypnotic activity (69). In another study, inhalation of the vapor of chamomile oil reduced a stressinduced increase in plasma adrenocorticotropic hormone (ACTH) levels. Diazepam co-administered with chamomile oil vapor further reduced ACTH levels, while flumazenile, a
BDZ antagonist, blocked the effect of chamomile oil vapor on ACTH. According to Paladini et al (70), the separation index (ratio between the maximal anxiolytic dose and the minimal sedative dose) for diazepam is 3 , while that of apigenin is 10 . Compounds other than apigenin present in extracts of chamomile can also bind BDZ and GABA receptors in the brain and may be responsible for some sedative effect; however, many of these compounds have yet to be identified.

Anxiety and seizure. Chamomile has been studied in the treatment of generalized anxiety disorder (GAD). Though the reports have been contradictory, one suggested that German chamomile resulted in the significant inhibition of GAD activity (71). Recent results from a controlled clinical trial on chamomile extract for GAD suggests that it may have modest anxiolytic activity in patients with mild to moderate GAD (72). Extracts of chamomile ( $M$. recutita) have notable effects on seizure induced by picrotoxin (73). Furthermore, apigenin has been shown to reduce latency in the onset of picrotoxininduced convulsions and the reduction of locomotor activity, but did not demonstrate any anxiolytic, myorelaxant, or anticonvulsant activities (16).

Diabetes. Studies have suggested that chamomile ameliorates hyperglycemia and diabetic complications by suppressing blood sugar levels, increasing liver glycogen storage and inhibiting sorbitol in human erythrocytes (74). The pharmacological activity of chamomile extract was shown to be independent of insulin secretion (75), and studies further revealed a protective effect on pancreatic $\beta$ cells due to the diminuation of hyperglycemia-related oxidative stress (76). Additional studies are required to evaluate the usefulness of chamomile in managing diabetes.

Sore throat/hoarseness. The efficacy of lubrication of the endotracheal tube cuff with chamomile before intubation on postoperative sore throat and hoarseness was determined in a randomized double-blind study. One hundred and sixty-one patients with an American Society of Anesthesiologists (ASA) physical status of I or II, undergoing elective surgical, orthopedic, gynecological or urological surgeries, were divided into two groups. The study group received 10 puffs of chamomile extract (Kamillosan M spray, total $370 \mathrm{mg}$ of Chamomile extract) at the site of the cuff of the endotracheal tube for lubrication, while the control group did not receive any lubrication before intubation. Standard general anesthesia with tracheal intubations was applied in both groups. Forty-one of 81 patients $(50.6 \%)$ in the chamomile group reported no postoperative incidences of sore throat in the post-anesthesia care unit, compared with 45 of 80 patients $(56.3 \%)$ in the control group; therefore there was no statistical significance between postoperative cases of sore throat and hoarseness in either the post-anesthesia care unit or at $24 \mathrm{~h}$ post operation, indicating that lubrication of the endotracheal tube cuff with chamomile extract spray before intubation does not prevent postoperative sore throat and hoarseness (77). Similar results were obtained in another double-blind study (21).

Vaginitis. Vaginal inflammation is common in women of all ages. Vaginitis is associated with itching, vaginal discharge, or 
pain with urination. Atrophic vaginitis most commonly occurs in menopausal and postmenopausal women, and its occurrence is often associated with reduced levels of estrogen. Chamomile douche may improve the symptoms of vaginitis with few side effects (78), yet there are insufficient research data to allow conclusions to be drawn concerning the possible potential benefits of chamomile in the treatment of this condition.

Wound healing. The efficacy of the topical use of chamomile to enhance wound healing was evaluated in a double-blind trial on 14 patients who underwent dermabrasion of tattoos. The effects on drying and epithelialization were observed, and chamomile was judged to be statistically efficacious in producing wound drying and in speeding epithelialization (79). The antimicrobial activity of the extract against various microorganisms was also assessed. The test group on day 15 exhibited a greater reduction in the wound area as compared to the controls (61 vs. 48\%), faster epithelialization, and a significantly higher wound-breaking strength. In addition, wet and dry granulation tissue weight and hydroxyproline content were significantly higher. The increased rate of wound contraction, together with the increased wound-breaking strength, hydroxyproline content and histological observations, support the use of $M$. recutita in wound management (80). Recent studies suggest that chamomile caused faster complete wound healing than corticosteroids (81). However, further studies are needed before it can be considered for clinical use.

Quality of life in cancer patients. Essential oils obtained from Roman chamomile are the basic ingredients of aromatherapy. Clinical trials of aromatherapy in cancer patients have shown no statistically significant differences between treated and untreated patients (82). Another pilot study investigated the effects of aromatherapy massage on anxiety and self-esteem in Korean elderly women. A quasi-experimental control group pretest-posttest design included 36 elderly females: 16 in the experimental group and 20 in the control group. Aromatherapy massage using lavender, chamomile, rosemary and lemon was administered to the experimental group only. Each massage session lasted 20 min and was performed 3 times per week for 2 to 3 -week periods with an intervening 1-week break. The intervention produced significant differences in anxiety and self-esteem. These results suggest that aromatherapy massage exerts positive effects on anxiety and self-esteem (83-85). However, more objective, clinical measures should be applied in a future study with a randomized placebo-controlled design.

\section{Contraindications and safety issues with chamomile}

A relatively low percentage of people are sensitive to chamomile and develop allergic reactions (86). People sensitive to ragweed and chrysanthemums or other members of the Compositae family are more prone to develop contact allergies to chamomile, particularly if they take other drugs that trigger the sensitization. A large-scale clinical trial was conducted between 1985 and 1991 in Hamburg, Germany, to study the development of contact dermatitis secondary to exposure to a mixture of components derived from the Compositae family. Twelve species of the Compositae family, including German chamomile, were selected and tested individually when the mixture induced allergic reactions. During the study, 3,851 individuals were tested using a patch with the plant extract (87). Of these patients, 118 (3.1\%) experienced an allergic reaction. Further tests revealed that feverfew elicited the most allergic reactions $(70.1 \%$ of patients) followed by chrysanthemums $(63.6 \%)$ and tansy $(60.8 \%)$. Chamomile fell in the middle range (56.5\%). A study involving 686 subjects exposed to either a sesquiterpene lactone mixture or a mixture of Compositae extracts led to allergic reactions in $4.5 \%$ of the subjects (88). In another study, it was shown that eye washing with chamomile tea in hay fever patients who had conjunctivitis exacerbated the eye inflammation, whereas no worsening of eye inflammation was noted when chamomile tea was ingested orally (89). Chamomile is listed on the FDA's GRAS (generally recognized as safe) list. It is possible that some reports of allergic reactions to chamomile may be due to the contamination of chamomile by 'dog chamomile', a highly allergenic and bad-tasting plant of similar appearance. Evidence of cross-reactivity of chamomile with other drugs is not well documented, and further study of this issue is required prior to reaching conclusions. Safety in young children, pregnant or nursing women, or those with liver or kidney disease has not been established, although there have not been any credible reports of toxicity caused by this common tea beverage.

\section{Conclusions}

Chamomile has been used as a herbal medication since ancient times, is still popular today, and will probably continue to be used in the future, as it contains various bioactive phytochemicals that provide therapeutic effects. Chamomile can aid in improving cardiovascular conditions, stimulates the immune system and provides some protection against cancer. Establishing whether or not the therapeutic effects of chamomile are beneficial to patients requires further research and the generation of scientific evidence. There is a need for continued efforts that focus on pre-clinical studies with chamomile involving animal models of various diseases. These results may then be validated in clinical trials with the aim of developing chamomile as a promising therapeutic agent. Without such evidence, it remains unclear whether these untested and unproven medical treatments are truly beneficial. It can be concluded that the discriminate and proper use of chamomile preparations is safe and provides therapeutic benefits; however, its indiscriminate or improper use may be unsafe and harmful.

\section{Acknowledgements}

The original work from the laboratory of the authors outlined in this review was supported by US Public Health Service grants RO1 AT002709 and RO1 CA108512.

\section{References}

1. Newman DJ, Cragg GM and Snader KM: Natural products as sources of new drugs over the period 1981-2002. J Nat Prod 66: 1022-1037, 2003.

2. Koehn FE and Carter GT: The evolving role of natural products in drug discovery. Nat Rev Drug Discov 4: 206-220, 2005. 
3. Jones WP, Chin YW and Kinghorn AD: The role of pharmacognosy in modern medicine and pharmacy. Curr Drug Targets 7: 247-264, 2006

4. Philip RB: Herbal remedies: the good, the bad, and the ugly. J Comp Integ Med 1: 1-11, 2004.

5. Fabricant DS and Farnsworth NR: The value of plants used in traditional medicine for drug discovery. Environ Health Perspect 109: 69-75, 2001.

6. Hadley SK and Petry JJ: Medicinal herbs: a primer for primary care. Hosp Pract 34: 105-116, 1999.

7. Astin JA, Pelletier KR, Marie A and Haskell WL: Complementary and alternative medicine use among elderly persons: one year analysis of Blue Shield medicare supplement. J Gerontol 55: M4-M9, 2000.

8. Hansen HV and Christensen KI: The common chamomile and the scentless may weed revisited. Taxon 58: 261-264, 2009.

9. Der MA and Liberti L: Natural Product Medicine: A Scientific Guide to Foods, Drugs, Cosmetics. George F. Stickley Co., Philadelphia, 1988.

10. Mann C and Staba EJ: Herbs, spices and medicinal plants: recent advances in botany. In: Horticulture and Pharmacology. Craker E and Simon JE (eds). Oryx Press, Phoenix, pp235-280, 1986.

11. McKay DL and Blumberg JB: A review of the bioactivity and potential health benefits of chamomile tea (Matricaria recutita L.). Phytother Res 20: 519-530, 2000.

12. Lemberkovics E, Kéry A, Marczal G, Simándi B and Szöke E: Phytochemical evaluation of essential oils, medicinal plants and their preparations. Acta Pharm Hung 68: 141-149, 1998.

13. Baser KH, Demirci B, Iscan G, et al: The essential oil constituents and antimicrobial activity of Anthemis aciphylla BOISS Var. discoidea BOISS. Chem Pharm Bull 54: 222-225, 2006.

14. Babenko NA and Shakhova EG: Effects of Chamomilla recutita flavonoids on age-related liver sphingolipid turnover in rats. Exp Gerontol 41: 32-39, 2006.

15. Redaelli C, Formentini L and Santaniello E: Reversed-phase high-performance liquid chromatography analysis of apigenin and its glucosides in flowers of Matricaria chamomilla and chamomile extracts. Planta Med 42: 288-292, 1981.

16. Avallone R, Zanoli P, Puia G, Kleinschnitz M, Schreier P and Baraldi M: Pharmacological profile of apigenin, a flavonoid isolated from Matricaria chamomilla. Biochem Pharmacol 59: 1387-1394, 2000.

17. Svehliková V, Bennett RN, Mellon FA, et al: Isolation, identification and stability of acylated derivatives of apigenin 7-O-glucoside from chamomile (Chamomilla recutita [L.] Rauschert). Phytochemistry 65: 2323-2332, 2004.

18. Srivastava JK and Gupta S: Antiproliferative and apoptotic effects of chamomile extract in various human cancer cells. J Agric Food Chem 55: 9470-9478, 2007.

19. Carnat A, Carnat AP, Fraisse D, Ricoux L and Lamaison JL: The aromatic and polyphenolic composition of Roman camomile tea. Fitoterapia 75: 32-38, 2004.

20. Hamon N: Herbal medicine. The chamomiles. Can Pharm J 612 , 1989.

21. Kyokong O, Charuluxananan S, Muangmingsuk V, Rodanant $\mathrm{O}$, Subornsug K and Punyasang W: Efficacy of chamomile-extract spray for prevention of post-operative sore throat. J Med Assoc Thai 85: 180-185, 2002

22. Fidler P, Loprinzi CL, O'Fallon JR, Leitch JM, Lee JK, Hayes DL, Novotny P, Clemens-Schutjer D, Bartel J and Michalak JC: Prospective evaluation of a chamomile mouthwash for prevention of 5-FU induced oral mucositis. Cancer 77: 522-525, 1996.

23. Mazokopakis EE, Vrentzos GE, Papadakis JA, Babalis DE and Ganotakis ES: Wild chamomile (Matricaria recutita L.) mouthwashes in methotrexate-induced oral mucositis. Phytomedicine 12: 25-27, 2005.

24. Anderson C, Lis-Balchin M and Kirk-Smith M: Evaluation of massage with essential oils on childhood atopic eczema. Phytother Res 14: 452-456, 2000.

25. Wilkinson S, Aldridge J, Salmon I, Cain E and Wilson B: An evaluation of aromatherapy massage in palliative care. Palliat Med 13: 409-417, 1999.

26. Scala G: Acute, short-lasting rhinitis due to chamomile-scented toilet paper in patients allergic to Compositae. Int Arch Allergy Immunol 139: 330-333, 2006.

27. Thornfeldt C: Cosmeceuticals containing herbs: fact, fiction, and future. Dermatol Surg 7: 873-880, 2005.

28. Weiss RF: Herbal Medicine. Arcanum AB (ed). Beaconsfield Publishers, Beaconsfield, pp22-28, 1988.
29. Rombi M: Cento Piante Medicinali. Nuovo Insttuto d'Arti Grafiche, Bergamo, Italy pp63-65, 1993

30. Awang DVC: Tyler's Herbs of Choice: The Therapeutic Use of Phytomedicinals. Taylor and Francis Group, CRC Press, New York, 2006.

31. Martens D: Chamomile: the herb and the remedy, J Chiropract Acad Homeo 6: 15-18, 1995.

32. Newall CA, Anderson LA and Phillipson JD: Herbal Medicine: A Guide for Health Care Professionals. Pharmaceutical Press, London, pp296, 1996.

33. Forster HB, Niklas H and Lutz S: Antispasmodic effects of some medicinal plants. Planta Med 40: 309-319, 1980.

34. Crotteau CA, Wright ST and Eglash A: Clinical inquiries; what is the best treatment for infants with colic? J Fam Pract 55: 634-636, 2006.

35. Sakai $\mathrm{H}$ and Misawa M: Effect of sodium azulene sulfonate on capsaicin-induced pharyngitis in rats. Basic Clin Pharmacol Toxicol 96: 54-55, 2005

36. Peña D, Montes de Oca N and Rojas S: Anti-inflammatory and anti-diarrheic activity of Isocarpha cubana Blake. Pharmacol Online 3: 744-749, 2006.

37. Merfort I, Heilmann J, Hagedorn-Leweke U and Lippold BC: In vivo skin penetration studies of camomile flavones. Pharmazie 49: 509-511, 1994

38. Srivastava JK, Pandey M and Gupta S: Chamomile, a novel and selective Cox-2 inhibitor with anti-inflammatory activity. Life Sci 85: 663-669, 2009.

39. Way TD, Kao MC and Lin JK: Apigenin induces apoptosis through proteasomal degradation of HER2/neu in HER2/ neu-overexpressing breast cancer cells via the phosphatidylinositol-3'-kinase/Akt-dependent pathway. J Biol Chem 279: 4479-4489, 2004.

40. Birt DF, Mitchell D, Gold B, Pour P and Pinch HC: Inhibition of ultraviolet light induced skin carcinogenesis in SKH-1 mice by apigenin, a plant flavonoid. Anticancer Res 17: 85-91, 1997.

41. Patel D, Shukla S and Gupta S: Apigenin and cancer chemoprevention: progress, potential and promise. Int J Oncol 30: 233-245, 2007.

42. Gates MA, Tworoger SS, Hecht JL, De Vivo I, Rosner B and Hankinson SE: A prospective study of dietary flavonoid intake and incidence of epithelial ovarian cancer. Int $\mathbf{J}$ Cancer 121: 2225-2232, 2007

43. Shukla S, Mishra A, Fu P, MacLennan GT, Resnick MI and Gupta S: Up-regulation of insulin-like growth factor binding protein-3 by apigenin leads to growth inhibition and apoptosis of 22Rv1 xenograft in athymic nude mice. FASEB J 19: 2042-2044, 2005.

44. Evans S, Dizeyi N, Abrahamsson PA and Persson J: The effect of a novel botanical agent TBS-101 on invasive prostrate cancer in animal models. Anticancer Res 10: 3917-3924, 2009.

45. Saller R, Beschomer M and Hellenbrecht D: Dose dependency of symptomatic relief of complaints by chamomile steam inhalation in patients with common cold. Eur J Pharmacol 183: 728-729, 1990.

46. Hertog MG, Feskens EJ, Hollman PC, Katan MB and Kromhout D: Dietary antioxidant flavonoids and risk of coronary heart disease: the Zutphen Elderly Study. Lancet 342: 1007-1011, 1993.

47. Gould L, Reddy CV and Gomprecht RF: Cardiac effects of chamomile tea. J Clin Pharmacol 11: 475-479, 1973.

48. Gardiner P: Complementary, holistic, and integrative medicine: chamomile. Pediatr Rev 28: 16-18, 2007.

49. Kell T: More on infant colic. Birth Gaz 13: 3, 1997.

50. Nissen HP, Blitz $H$ and Kreyel HW: Prolifometrie, eine methode zur beurteilung der therapeutischen wirsamkeit kon Kamillosan ${ }^{\circledR}$-Salbe. Z Hautkr 63: 84-90, 1988.

51. Albring M, Albrecht $\mathrm{H}$, Alcorn $\mathrm{G}$ and Lüker PW: The measuring of the anti-inflammatory effect of a compound on the skin of volunteers. Meth Find Exp Clin Pharmacol 5: 75-77, 1983.

52. Patzelt-Wenczler R and Ponce-Pöschl E: Proof of efficacy of Kamillosan ${ }^{\circledR}$ cream in atopic eczema. Eur J Med Res 5: 171-175, 2000.

53. Kroll U and Cordes C: Pharmaceutical prerequisites for a multitarget therapy. Phytomedicine 5: 12-19, 2006.

54. Khayyal MT, Seif-El-Nasr M, El-Ghazaly MA, Okpanyi SN, Kelber $\mathrm{O}$ and Weiser D: Mechanisms involved in the gastroprotective effect of STW 5 (Iberogast) and its components against ulcers and rebound acidity. Phytomedicine 13: 56-66, 2006. 
55. Lyseng-Williamson KA and Perry CM: Micronised purified flavonoid fraction: a review of its use in chronic venous insufficiency, venous ulcers, and haemorrhoids. Drugs 63: 71-100, 2003.

56. Misra MC and Parshad R: Randomized clinical trial of micronized flavonoids in the early control of bleeding from acute internal haemorrhoids. Br J Surg 87: 868-872, 2000

57. Wang Y, Tang H, Nicholson JK, Hylands PJ, Sampson J and Holmes E: A metabonomic strategy for the detection of the metabolic effects of chamomile (Matricaria recutita L.) ingestion. J Agric Food Chem 53: 191-196, 2005.

58. Zeggwagh NA, Moufid A, Michel JB and Eddouks $M$ Hypotensive effect of Chamaemelum nobile aqueous extract in spontaneously hypertensive rats. Clin Exp Hypertens 31: 440-450, 2009.

59. Ramos-e-Silva M, Ferreira AF, Bibas R and Carneiro S: Clinical evaluation of fluid extract of Chamomilla recutita for oral aphthae. J Drugs Dermatol 5: 612-617, 2006.

60. Wu J: Treatment of rosacea with herbal ingredients. J Drugs Dermatol 5: 29-32, 2006

61. Graf J: Herbal anti-inflammatory agents for skin disease. Skin Ther Lett 5: 3-5, 2000.

62. Weseler A, Geiss HK, Saller R and Reichling JA: Novel colorimetric broth microdilution method to determine the minimum inhibitory concentration (MIC) of antibiotics and essential oils against Helicobacter pylori. Pharmazie 60: 498-502, 2005.

63. Fugh-Berman A: Herbal supplements: indications, clinical concerns, and safety. Nutr Today 37: 122-124, 2002.

64. Wechselberger G, Schoeller T, Otto A, Obrist P, Rumer A and Deetjen H: Total gluteal pouching with pseudoanus caused by burn injury: report of a case. Dis Colon Rectum 41: 929-931, 1998.

65. Tubaro A, Zilli C, Redaelli C and Della Loggia R: Evaluation of antiinflammatory activity of a chamomile extract after topical application. Planta Med 50: 359, 1984

66. Gonsalves WC, Wrightson AS and Henry RG: Common oral conditions in older persons. Am Fam Physician 78: 845-852, 2008.

67. Kassi E, Papoutsi Z, Fokialakis N, Messari I, Mitakou S and Moutsatsou P: Greek plant extracts exhibit selective estrogen receptor modulator (SERM)-like properties. J Agric Food Chem 52: 6956-6961, 2004.

68. Avallone R, Zanoli P, Corsi L, Cannazza G and Baraldi M: Benzodiazepine compounds and GABA in flower heads of Matricaria chamomilla. Phytother Res 10: 177-179, 1996.

69. Shinomiya K, Inoue T, Utsu Y, Tokunaga S, Masuoka T, Ohmori A and Kamei C: Hypnotic activities of chamomile and passiflora extracts in sleep-disturbed rats. Biol Pharm Bull 28 808-810, 2005

70. Paladini AC, Marder M, Viola H, Wolfman C, Wasowski C and Medina JH: Flavonoids and the central nervous system: from forgotten factors to potent anxiolytic compounds. J Pharm Pharmacol 51: 519-526, 1999.

71. Awad R, Levac D, Cybulska P, Merali Z, Trudeau VL and Arnason JT: Effects of traditionally used anxiolytic botanicals on enzymes of the gamma-aminobutyric acid (GABA) system. Can J Physiol Pharmacol 85: 933-942, 2007.

72. Amsterdam JD, Li Y, Soeller I, Rockwell K, Mao JJ and Shults J: A randomized, double-blind, placebo-controlled trial of oral Matricaria recutita (Chamomile) extract therapy for generalized anxiety disorder. J Clin Psychopharmacol 29: 378-382, 2009.

73. Herdari MR, Dadollahi Z, Mehrabani M, Mehrabi H, PourzadehHosseini M, Behravan E and Etemad L: Study of antiseizure effects of Matricaria recutita extract in mice. Ann NY Acad Sci 1171: 300-304, 2009.
74. Kato A, Minoshima Y, Yamamoto J, Adachi I, Watson AA and Nash RJ: Protective effects of dietary chamomile tea on diabetic complications. J Agric Food Chem 56: 8206-8211, 2008.

75. Eddouks M, Lemhadri A, Zeggwah NA and Michel JB: Potent hypoglycaemic activity of the aqueous extract of Chamaemelum nobile in normal and streptozotocin-induced diabetic rats. Diabetes Res Clin Pract 67: 189-195, 2005.

76. Cemek M, Kaga S, Simsek N, Buyukokuroglu ME and Konuk M: Antihyperglycemic and antioxidative potential of Matricaria chamomilla L. in streptozotocin-induced diabetic rats. J Nat Med 62: 284-293, 2008.

77. Charuluxananan S, Sumethawattana $\mathrm{P}$, Kosawiboonpol R, Somboonviboon $\mathrm{W}$ and Werawataganon T: Effectiveness of lubrication of endotracheal tube cuff with chamomile-extract for prevention of postoperative sore throat and hoarseness. J Med Assoc Thai 87: 185-189, 2004.

78. Benetti C and Manganelli F: Clinical experiences in the pharmacological treatment of vaginitis with a camomile-extract vaginal douche. Minerva Ginecol 37: 799-801, 1985.

79. Glowania HJ, Raulin C and Swoboda M: Effect of chamomile on wound healing - a clinical double-blind study. Z Hautkr 62: 1267-1271, 1987.

80. Nayak BS, Raju SS and Rao AV: Wound healing activity of Matricaria recutita L. extract. J Wound Care 16: 298-302, 2007.

81. Martins MD, Marques MM, Bussadori SK, Martins MA, Pavesi VC, Mesquita-Ferrari RA and Fernandes KP: Comparative analysis between Chamomilla recutita and corticosteroids on wound healing. An in vitro and in vivo study. Phytother Res 23: 274-278, 2009 .

82. Wilcock A, Manderson C, Weller R, Walker G, Carr D, Carey AM, Broadhurst D, Mew J and Ernst E: Does aromatherapy massage benefit patients with cancer attending a specialist palliative care day centre? Palliat Med 18: 287-290, 2004.

83. Soden K, Vincent K, Craske S, Lucas C and Ashley S: A randomized controlled trial of aromatherapy massage in a hospice setting. Palliat Med 18: 87-92, 2004.

84. Graham PH, Browne L, Cox $\mathrm{H}$ and Graham J: Inhalation aromatherapy during radiotherapy: results of a placebocontrolled double-blind randomized trial. J Clin Oncol 21: 2372-2376, 2003

85. Hadfield $\mathrm{N}$ : The role of aromatherapy massage in reducing anxiety in patients with malignant brain tumours. Int J Palliat Nurs 7: 279-285, 2001

86. Budzinski JW, Foster BC, Vandenhoek S and Arnason JT: An in vitro evaluation of human cytochrome P450 3A4 inhibition by selected commercial herbal extracts and tinctures. Phytomedicine 7: 273-282, 2000.

87. Hausen BM: A 6-year experience with a Compositae mix. Am J Contact Dermat 7: 94-99, 1996.

88. Paulsen E, Andersen KE and Hausen BM: Compositae dermatitis in a Danish dermatology department in one year (I). Results of routine patch testing with the sesquiterpene lactone mix supplemented with aimed patch testing with extracts and sesquiterpene lactones of Compositae plants. Contact Dermatitis 29: 6-10, 1993.

89. Subiza J, Subiza JL, Alonso M, Hinojosa M, Garcia R, Jerez M and Subiza E: Allergic conjunctivitis to chamomile tea. Ann Allergy 65: 127-132, 1990. 